\title{
Cluster Analysis on the Development of Agricultural Economy in the Cities (Zone) of Shaanxi
}

\author{
Yong LI \\ Ankang University, Ankang, China
}

\begin{abstract}
In this paper, a system for evaluating the development of agricultural economy is developed with nine Level III indicators. By cluster analysis, the 11 cities (zone) of Shaanxi are divided into three classes, including leading areas in agricultural economy, relatively developed areas in agricultural economy, and developing areas in agricultural economy. In combination with correlation analysis, major factors affecting the development of agricultural economy in Shaanxi are obtained, and some suggestions are provided for improving the development of agricultural economy.
\end{abstract}

KEYWORD: rural economic development: Shaanxi; cluster analysis; correlation analysis

\section{RESEARCH BACKGROUND}

Shaanxi is a province located in the west of China, under the jurisdiction of which there are ten cities and one demonstration zone. It is the most developed province in industry and agriculture in Northwest China. By geographical location, Shaanxi is divided into three parts, including Central Shaanxi Plain, Northern Shaanxi and Southern Shaanxi. Traditionally, the development conditions of agricultural economy in this province are also divided into three sections by geographical location, including the conditions in Central Shaanxi Plain, Northern Shaanxi and Southern Shaanxi. However, this paper, no longer following the traditional division method, divides the development conditions of agricultural economy in the cities (zone) of Shaanxi according to development indicators of agricultural economy. Through clustering and relevant analysis, it investigates the development conditions of agricultural economy in the cities (zone) of Shaanxi.

\section{EVALUATION INDICATOR SYSTEM AND EVALUATION METHOD}

\subsection{Establishment of Evaluation Indicator System}

At present, there are no unanimous views in the academic circle as to the method for evaluation of the development level of agricultural economy and construction of the indicator system. On the basis of a study on the indicators of various models, according to the requirement that the indicator evaluation system should have comprehensive coverage, reasonable structure, proper simplicity and complexity and strong representativeness, and following the scientific, objective, systematic, feasible and comparable principles, the author sets the agricultural development levels of the cities (zone) in Shaanxi as an evaluation indicator system consisting of indicators at three levels. These indicators include one Level I indicator (i.e., the agricultural development level), three Level II indicators, and nine Level III indicators. See Table 1 for details of the indicators.

\subsection{Data Collection and Processing}

The original data used in this paper are all from Shaanxi Statistical Yearbook 2014, and partial data are obtained by calculation and sorting based on the original data. Since these data have different dimensions and orders of magnitude, they cannot be directly used for evaluation. In order to ensure the reliability of results, it is necessary to normalize the original indicator data. In this paper, the technique of z-score normalization is applied, by which the original data values are converted to new data, i.e., new data $=($ original data - mean value $) /$ standard deviation.

\subsection{Evaluation Method}

This paper adopts cluster analysis to evaluate the indicator data. Cluster analysis is a statistical 
classification technique in which samples (individuals) are sub-divided into groups such that the items in a cluster are very similar to one another. By cluster analysis, we can divide the agricultural development levels of different samples into several classes, thus to find the similarity in the same class and the diversity among different classes. This will facilitate research and development of corresponding countermeasures and policies. In this paper, the hierarchical cluster method, SPSS software and squared Euclidean distance are used to calculate the similarity among the 11 cities (zone) of Shaanxi; meanwhile, Ward's method is applied in cluster analysis.

Table 1 Indicator System for Evaluation of Agricultural Development Level

\begin{tabular}{|c|c|c|}
\hline $\begin{array}{l}\text { Level II } \\
\text { Indicators }\end{array}$ & Level III Indicators & Unit \\
\hline $\begin{array}{l}\text { Agricultural } \\
\text { Foundation }\end{array}$ & $\begin{array}{l}\text { The Average Area of Cultivated } \\
\text { Land per Rural Person } \\
\text { Percentage of Effective Irrigated } \\
\text { Area in Cultivated Area }\end{array}$ & $\begin{array}{l}\text { hm2/person } \\
\%\end{array}$ \\
\hline $\begin{array}{l}\text { Agricultural } \\
\text { Production } \\
\text { Input }\end{array}$ & $\begin{array}{l}\text { Machinery Power per Hectare of } \\
\text { Cultivated Area } \\
\text { Average Consumption of Chemical } \\
\text { Fertilizers per Hectare of Cultivated } \\
\text { Area } \\
\text { Average Consumption of Plastic } \\
\text { Film per Hectare of Cultivated Area }\end{array}$ & $k w$ \\
\hline $\begin{array}{l}\text { Agricultural } \\
\text { Benefit }\end{array}$ & $\begin{array}{l}\text { Per Capita Annual Net Income of } \\
\text { Rural Households } \\
\text { Grain Yield per Unit Area } \\
\text { Oil-bearing Crop Yield per Unit } \\
\text { Area } \\
\text { Vegetable Yield per Unit Area }\end{array}$ & $\begin{array}{l}\text { yuan } \\
\mathrm{kg} / \mathrm{hm} 2 \\
\mathrm{~kg} / \mathrm{hm} 2 \\
\mathrm{~kg} / \mathrm{hm} 2\end{array}$ \\
\hline
\end{tabular}

\section{CLUSTERING RESULTS AND DISCUSSION}

\subsection{Hierarchical Cluster Diagram and Classification}

Table 2 Cluster Membership

\begin{tabular}{|l|l|}
\hline Case & 3 Clusters \\
\hline 1:Xi'an & 2 \\
\hline 2:Tongchuan & 3 \\
\hline 3:Baoji & 3 \\
\hline 4:Xianyang & 2 \\
\hline 5:Weinan & 3 \\
\hline 6:Yan'an & 3 \\
\hline 7:Hanzhong & 3 \\
\hline 8:Yulin & 3 \\
\hline 9:Ankang & 3 \\
\hline 10:Shangluo & 3 \\
\hline 11:Yangling & 1 \\
\hline
\end{tabular}

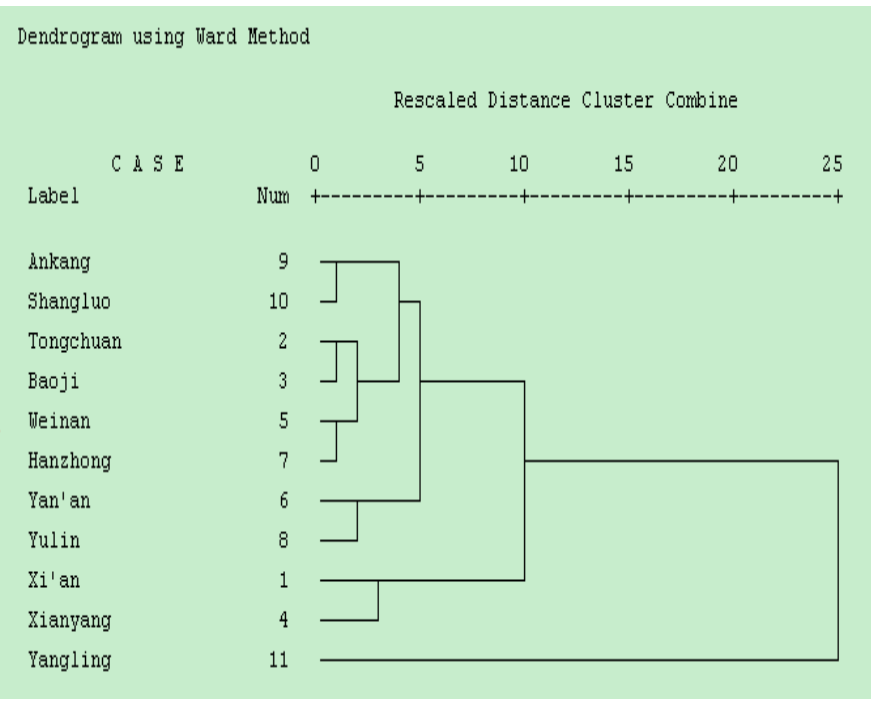

Fig. 1 Dendrogram

Table 2 lists the cluster members after data clustering by use of SPSS software, and Fig. 1 shows the tree diagram:

According to Table 1 and Fig. 1, the development conditions of agricultural economy in the cities (zone) of Shaanxi can be divided into three classes: Class I covers Yangling Demonstration Zone, referring to leading areas in agricultural economy; Class II covers the cities of Xi'an and Xian yang, referring to relatively developed areas in agricultural economy; Class III covers the cities of Tongchuan, Baoji, Wei nan, Yan'an, Hanzhong, Yulin, Ankang and Shangluo, referring to developing areas in agricultural economy.

\subsection{Agricultural Foundation and Development of Agricultural Economy}

In this paper, the average area of cultivated land per rural person and the percentage of effective irrigated area in cultivated area are used to represent the condition of agricultural foundation in the respective area. From the classification results, it can be seen that the percentage of effective irrigated area in cultivated area is closely related to the development condition of agricultural economy. On the one hand, the value of this indicator reaches 94.78 in Yangling Demonstration Zone which falls into Class I, ranking first among all areas; in Xi' an and Xianyang of Class II, this indicator is calculated according to simple arithmetic mean (to allow easy and simple calculation and meet the requirement of problem explanation, this paper uses the simple arithmetic mean instead of weighted average for calculation) and the calculated value is 65.27; as for the areas of Class III, the value of this indicator calculated according to the simple arithmetic mean is 32.29. Comparatively, the indicator value in Class III is significantly lower than the other two classes. On the other hand, the correlation between the percentage of effective irrigated area in cultivated area and the per 
capita annual net income of rural households is analyzed using the data in this paper; the coefficient of correlation is 0.642 , which also suggests that the percentage of effective irrigated area in cultivated area is a major factor in the agricultural development of an area. The correlation between the average area of cultivated land per rural person and the per capita annual net income of rural households is analyzed; the coefficient of correlation is -0.231 , failing the correlation test. From the values of this indicator in the three classes of areas, we can also find that the average area of cultivated land per rural person is not a major factor affecting the development condition of agricultural economy.

\subsection{Agricultural Production Input and Development of Agricultural Economy}

Table 2 Classification Data of Agricultural Production Input

\begin{tabular}{|l|l|l|l|}
\hline & $\begin{array}{l}\text { Machinery Power per } \\
\text { Hectare of Cultivated } \\
\text { Area }\end{array}$ & $\begin{array}{l}\text { Average Consumption of } \\
\text { Chemical Fertilizers per } \\
\text { Hectare of Cultivated Area }\end{array}$ & $\begin{array}{l}\text { Average Consumption of } \\
\text { Plastic Film per Hectare of } \\
\text { Cultivated Area }\end{array}$ \\
\hline Value of Class I & 19.77 & 820.14 & 121.22 \\
\hline Simple Arithmetic Mean of Class II & 10.59 & 1429.27 & 16.53 \\
\hline Simple Arithmetic Mean of Class III & 7.66 & 667.63 & 12.35 \\
\hline $\begin{array}{l}\text { Coefficient of Correlation with per Capita } \\
\text { Annual Net Income of Rural Households }\end{array}$ & 0.752 & 0.193 & 0.556 \\
\hline
\end{tabular}

In this paper, the machinery power per hectare of cultivated area, the average consumption of chemical fertilizers per hectare of cultivated area and the average consumption of plastic film per hectare of cultivated area are used to represent the condition of agricultural benefit in the respective area. Table 2 shows that the machinery power per hectare of cultivated area is significantly correlated with the per capita annual net income of rural households, and the coefficient of correlation reaches up to 0.752 . Larger machinery power represents higher degree of agricultural modernization and better development condition of agricultural economy, which is also proved by the data of simple arithmetic means of different classes. The average consumption of plastic film per hectare of cultivated area, which represents the application of protected agriculture, also has significant correlation with the per capita annual net income of rural households; the coefficient of correlation is 0.556 . From the table, it can be seen that the consumption in areas of Class I is much higher than the other two classes. The coefficient of correlation between the average consumption of chemical fertilizers per hectare of cultivated area and the per capita annual net income of rural households is 0.193 , which fails the correlation test. The data shown in the table also suggest that higher consumption of chemical fertilizers does not necessarily generate higher income. According to the survey, it is found that the excessive use of chemical fertilizers exists in rural areas of Shaanxi, but these areas have not gained the best economic benefit.

\subsection{Agricultural Benefit and Development of Agricultural Economy}

Table 3 Classification Data of Agricultural Benefit

\begin{tabular}{|c|c|c|c|c|}
\hline & $\begin{array}{l}\text { Per Capita Annual Net } \\
\text { Income of Rural } \\
\text { Households }\end{array}$ & \begin{tabular}{|l|} 
Grain Yield per \\
Unit Area
\end{tabular} & $\begin{array}{l}\text { Oil-bearing Crop } \\
\text { Yield per Unit } \\
\text { Area }\end{array}$ & $\begin{array}{l}\text { Vegetable } \\
\text { Yield per } \\
\text { Unit Area }\end{array}$ \\
\hline Value of Class I & 12435 & 6076 & 6000 & 64784 \\
\hline Simple Arithmetic Mean of Class II & 10734 & 4794 & 1829 & 43990 \\
\hline Simple Arithmetic Mean of Class III & 7669 & 3686 & 1861 & 28341 \\
\hline $\begin{array}{l}\text { Coefficient of Correlation with per Capita Annual Net } \\
\text { Income of Rural Households }\end{array}$ & & 0.807 & 0.534 & 0.783 \\
\hline
\end{tabular}

In this paper, the per capita annual net income of rural households, the grain yield per unit area, the oil-bearing crop yield per unit area and the vegetable yield per unit area are used to represent the condition of agricultural benefit in the respective area. According to Table 3, significant difference in the per capita annual net income of rural households can be found among the three classes of areas; higher income stands for better development of agricultural development. The grain yield per unit area and thevegetable yield per unit area are significantly correlated with the per capita annual net income of rural households, and the coefficients of correlation are 0.807 and 0.783, respectively; significant difference can be found among the three classes of areas according to the simple arithmetic means of these two indicators. The coefficient of correlation between the oil-bearing crop yield per unit area and 
the per capita annual net income of rural households is 0.543 , which passes the correlation test; a large gap exists between Class I and the other two classes in terms of the oil-bearing crop yield per unit area.

\section{CONCLUSION \& SUGGESTION}

Without following the traditional method of division by geographical location, this paper uses nine Level III indicators to cluster the development conditions of agricultural economy in the 11 cities (zone) of Shaanxi as three classes, including leading areas in agricultural economy, relatively developed areas in agricultural economy, and developing areas in agricultural economy. Significant difference can be found among these three classes in the data of per capita annual net income of rural households.

The percentage of effective irrigated area in cultivated area, the machinery power per hectare of cultivated area and the average consumption of plastic film per hectare of cultivated area are major factors that affect the development of agricultural economy; the increase of these data will have a remarkable impact on the development level of agricultural economy in the respective area.

According to the data in the cities (zone) of Shaanxi, the average area of cultivated land per rural person is not a major factor affecting the development of agricultural economy and should not be taken as an excuse for lagging development of agricultural economy. From the average consumption of chemical fertilizers per hectare of cultivated area in the cities (zone) of Shaanxi, we can see that some areas use chemical fertilizers excessively; it is suggested that specific investigations and tests should be carried out in relevant areas, so as to improve the efficiency of chemical fertilizers used.

There is significant difference among the three classes of areas in terms of the grain yield per unit area and the vegetable yield per unit area, indicating that there is still a lot of room for improvement in the development of agricultural economy in the areas of Class II and III. In the areas of Class I, the oilbearing crop yield per unit area is much higher than the other two classes, and no significant difference is found between the areas of Class II and III in this respect. It is suggested that in the areas of Class II and III, more efforts should be made to test and popularize the technologies used in the areas of Class I, thus to further increase the oil-bearing crop yield per unit area in the areas of Class II and III.

\section{REFERENCES}

[1] L.Kaufman, P.J.Rousseeuw. Finding Groups in Data: An introduction to cluster Analysis. New York: John Wiley \& Sons, 1990:126-163.

[2] Bonze D C, Hennoeilla AY. Clustering panel data via perturbed adaptive simulated annealing and genetic algorithms. Advances in Complex Systems, 2002(4): 339360.

[3] Yu-chen Song, Xiao-Liang Jia, Hai-Dong Meng. Combination Clustering Evaluation Research on Different Data Distribution Patterns. Advanced Materials Research, 2013.

[4] Daniel Barbara. Requirements for clustering data stream. ACM SIGKDD Explorations Newsletter, 2002, 3(2):23-27. 